\title{
QUALIFICAÇÃO PEDAGÓGICA DE ENFERMEIROS DOCENTES EM CURSOS PROFISSIONALIZANTES
}

\author{
Marden Cardoso Miranda Hott, Amanda Márcia dos Santos Reinaldo \\ Universidade Federal de Minas Gerais \\ DOI: $10.15628 /$ rbept.2018.6455
}

Artigo submetido em set/2018 e aceito em jul/2018

\begin{abstract}
RESUMO
O objetivo deste estudo foi conhecer a qualificação pedagógica de enfermeiros docentes de cursos técnicos em enfermagem, através de uma revisão narrativa da literatura publicada entre 2006 e 2016. Os achados sugerem que há necessidade de investimentos na formação para a docência com vista à construção dos saberes para o processo de ensinar. Acredita-se que este estudo possa ser de grande valia para chamar a atenção desses profissionais, das instituições que os formam e daquelas que os agrega como professores, para esta problemática, contribuindo assim para a melhoria do processo de ensino/aprendizagem e para a consequente elevação do nível da assistência à saúde da população.
\end{abstract}

Palavras-Chave: Educação em enfermagem. Educação continuada. Credenciamento.

\section{PEDAGOGICAL QUALIFICATION OF TEACHING NURSES IN VOCATIONAL COURSES}

\begin{abstract}
The objective of this study was to know the pedagogical qualification of teaching nurses in nursing technical courses, through a narrative review of the literature published between 2006 and 2016. The findings suggest that there is a need for investments in teaching for the construction of knowledge for the teaching process. It is believed that this study can be of great value to draw the attention of these professionals, the institutions that form them and those that add them as teachers, to this problem, thus contributing to the improvement of the teaching / learning process and consequent the level of health care for the population.
\end{abstract}

Keywords: Nursing Education. Continuing Education. Credentialing.

\section{APRESENTAÇÃO}

Os cuidados de enfermagem prestados à população em todos os níveis de atenção à saúde brasileira majoritariamente são desenvolvidos por pessoal Técnico em Enfermagem (TE). Cabe aos enfermeiros, profissionais estes graduados, proporcionar formação de qualidade ao nível profissionalizante, com vistas à otimização da assistência aos processos de saúde e doença (BRASIL, 1955). 
Diante desta responsabilidade, em 1968 foi estabelecida a Licenciatura como requisito para atuação dos enfermeiros na docência do ensino profissional de enfermagem (SECAF, 1987) Entretanto, apesar das leis regulamentares do exercício profissional da enfermagem e do ensino no Brasil dar foco a participação do enfermeiro licenciado em escolas profissionalizantes de nível TE, as delegacias de ensino permitem que não habilitados assumam as atividades pedagógicas, emitindo autorização provisória para a docência, perpetuando-a com a renovação dessa condição precária (BUENO et al, 1997).

Em contraponto à autorização formal da docência em título precário, as mesmas instituições que autorizam e regulam essa prática, não conferem validade instrumental às Especializações Pedagógicas, mesmo estas sendo devidamente reconhecidas pelo Ministério da Educação (MEC). Esses cursos de Pós-graduação, bem como a Licenciatura, balizam a formação dos enfermeiros para atuarem como docentes em escolas Técnicas em Enfermagem.

A educação profissional em enfermagem constrói a sua história percorrendo grandes enfrentamentos e diversos desafios para o exercício da docência, dentre eles a imperativa necessidade da qualificação adequada de seus professores (FRIEDLANDER et al, 1992). Contudo, mesmo que historicamente a fragilidade do corpo docente tenha sido percebida, esta problemática continua estendendo-se como um dos pontos mais críticos para a formação adequada do TE (CHIECO, 1989).

Diante da relevância da atuação do enfermeiro docente no processo de formação do TE e da necessidade de relacionar os conhecimentos da enfermagem enquanto ciência, aos conhecimentos do processo de ensino e aprendizagem, realizou-se este trabalho com o objetivo de conhecer a qualificação pedagógica de enfermeiros docentes de Cursos Técnicos em Enfermagem, por meio de uma revisão narrativa da literatura publicada entre 2006 e 2016.

O intuito é chamar a atenção dos enfermeiros, das instituições superiores que os formam e das escolas profissionalizantes que os agrega como professores, para a necessidade de investimentos na capacitação que vise à prática docente. Com isso, espera-se contribuir para a melhoria da profissionalização em enfermagem e para a consequente elevação da qualidade da assistência à saúde da população.

A seguir apresentamos a metodologia para a realização da pesquisa, o panorama da formação profissional em enfermagem, as revelações das publicações sobre o tema e a análise destes achados para se alcançar as considerações finais. 


\section{METODOLOGIA}

Trata-se de uma revisão narrativa da literatura com síntese qualitativa que tem por intuito conhecer a qualificação pedagógica de enfermeiros docentes em Cursos Técnicos em Enfermagem. Dada à amplitude, essa categoria de artigo não possui um protocolo padrão para sua elaboração, no entanto tem um papel fundamental para a educação continuada, pois permite ao leitor adquirir e atualizar o conhecimento sobre uma temática específica em curto espaço de tempo (ROTHER, 2007).

A busca de informações ocorreu entre julho e dezembro de 2016, sendo realizada no Portal de Periódicos CAPES; Medline (Medical Literature Analysis and Retrietal System On-line); Lilacs (Latin American and Caribean Health Science Literature Database), que possibilitam o acesso a diversas publicações científicas. Foram selecionados e analisados artigos originais, revisados por pares, publicados em português no período de 2006 a 2016, relacionados os termos "docência em enfermagem", "formação pedagógica de enfermeiros" e "licenciatura em enfermagem". As referências destes estudos também foram verificadas, a fim de suprir informações sobre o tema. As produções foram correlacionadas com "ensino profissionalizante".

Inicialmente foram encontradas 47 publicações, sendo que para a seleção dos artigos foram avaliados os títulos e resumos, quando incluídos nos requisitos, cumpria-se na íntegra a leitura. Excluíram-se os trabalhos que disponibilizavam apenas os resumos, bem como aqueles que não tratavam especificamente da relação entre formação profissional do Enfermeiro docente em cursos profissionalizantes de enfermagem. Desta forma, 13 artigos tornaram-se elegíveis para realização deste trabalho.

\section{DESAFIOS DO SER E DO FAZER DOCENTE}

\subsection{O Técnico em Enfermagem}

O Conselho Federal de Enfermagem aponta que em março de 2017 estavam cadastrados 1.942,492 profissionais, sendo $459.313(23,6 \%)$ Enfermeiros, $1.051,073$ (54,1\%) Técnicos em Enfermagem e 432.141 (22,3\%) Auxiliares de Enfermagem e Obstetrizes ou Atendentes (COFEN, 2017). O Instituto Brasileiro de Geografia e Estatísticas em seu mais recente censo apontou que cerca de $80 \%$ dos profissionais de enfermagem que atuam no Brasil são de nível auxiliar e técnico, formados nas 1.413 instituições de ensino profissionalizante de enfermagem em todo o país (IBGE, 2010).

Os dados demonstram que os profissionais que compõem a Equipe de Enfermagem representam um elevado contingente de trabalhadores da 
saúde, especialmente a nível profissionalizante, que integra a grande maioria. Desta forma, a sociedade há de se ater às questões que permeiam a qualidade da formação desta categoria, especialmente no que tange às questões relacionadas a quem e a como estes estão sendo formados para 0 mundo do trabalho.

A profissão de TE existente desde 1966, ano em que foi criado o primeiro curso na Escola Ana Néri, sediada na cidade do Rio de Janeiro. No entanto, a regulamentação para o exercício profissional ocorreu somente depois de transcorridos 20 anos da sua criação, sendo efetivamente legalizada em 1986, com a Lei no 7.498/86, regulamentada pelo Decreto-Lei ํo 94.406/87. A partir de então, a profissionalização dos trabalhadores de nível médio na área de enfermagem começou a se expandir.

O TE é um profissional que lida direta e diuturnamente com a assistência de enfermagem, portanto pode intensificar os problemas de saúde da população colocando em risco a vida de seus pacientes ao receber uma formação profissional deficitária. Desta forma, vale ressaltar que a qualidade do cuidado prestado à saúde da população tem estreita relação com o processo de educação de seus trabalhadores. Espera-se destes uma formação profissional baseada em propostas pedagógicas que privilegiem o ensino e a aprendizagem de forma participativa e reflexiva, determinantes para a melhoria da assistência, especialmente no âmbito do Sistema Único de Saúde (GÓES et al, 2015).

São os enfermeiros, profissionais com graduação de nível superior, que se apropriam da responsabilidade direta de formar o TE com habilidade e competência para intervir nos processos de promoção da saúde, prevenção da doença, cuidados e bem-estar da população. Assim, entende-se que seja de suma importância o envolvimento de todos os graduados, tanto na assistência, quanto na docência, com a profissionalização em enfermagem, considerando que o binômio saúde-educação não deve ser destituído com vistas à integralidade do processo de formação.

Diante desta perspectiva, faz-se necessário repensar a formação do docente a nível profissionalizante com vista à formação do profissional TE comprometido com a transformação social, ético, crítico e reflexivo (GÓES et al, 2015). Neste sentido, torna-se relevante considerar as lacunas que dificultam esse ideário.

\subsection{Cenário atual da formação do enfermeiro docente}

Os cursos de Graduação em Enfermagem apresentam deficiências na formação dos enfermeiros para a atividade docente, considerando a inexistência de disciplinas de cunho pedagógico que norteiem o processo de aprendizagem, embasado por teorias cognitivas sustentáveis. Com vistas ao 
mercado de trabalho para o ensino de enfermagem, que constitui hoje uma considerável parte da área que emprega enfermeiros, pode-se dizer que estão formando profissionais descontextualizados das reais necessidades do setor (FERREIRA-JÚNIOR, 2008).

No entanto, os cursos de Licenciatura em Enfermagem, Formação Pedagógica ou Docência para Educação Profissional de Nível Técnico na Área da Saúde, são opções para qualificação que poderão conduzir o enfermeiro ao desenvolvimento de novos saberes. Integrando o conhecimento adquirido na graduação ao conhecimento da didática e pedagogia, os enfermeiros estarão melhor preparados para o exercício docente. Nas competências do professor esses conhecimentos são fundamentais para formação de TE's capacitados a atender as necessidades decorrentes de suas funções (VALENTE, 2006).

O Curso de Licenciatura em Enfermagem foi criado pelo Parecer no837/68, sendo aprovado em 6 de dezembro 1968 com objetivo de qualificar enfermeiros para o exercício docente. A licenciatura evidenciou-se nas décadas de 1980 e 1990, com a ampliação da oferta de cursos profissionalizantes, motivada inicialmente pelo Projeto de Profissionalização dos Trabalhadores da Área de Enfermagem (PROFAE) do Ministério da Saúde no ano 2000 e posteriormente pelo avanço da área profissionalizante no Brasil.

A Licenciatura em Enfermagem tem por finalidade capacitar o enfermeiro para utilização de estratégias e tecnologias pertinentes ao processo de ensino e aprendizagem de conteúdos específicos, bem como orientar quanto aos aspectos lógicos, psicológicos, pedagógicos e filosóficos da profissão (DUARTE, 2009). Apesar de a licenciatura ter sido atenuada pela Lei de Diretrizes de Bases da Educação (LDB) de 1996, que instituiu reformas em todos os campos de formação, posteriormente o Decreto 5.154/04 retomou a questão prevendo a partir de então a obrigatoriedade da licenciatura para os professores da educação profissional.

Contudo, um documento do MEC tem provocado dificuldade de interpretação e manutenção do Curso de Licenciatura em Enfermagem nas Universidades Federais: Ofício circular n. 02/2010CGOC/DESUP/SESU/MEC - assunto: Readequação de cadastro de curso no sistema e-MEC. Esse ofício desvincula os cursos tipo Bacharelado das Licenciaturas e institui uma carga horária quase equivalente a outra formação superior em enfermagem para o exercício da docência, cerca de 4 anos, o que inviabiliza a oferta do curso pelas Universidades e desestimula 0 interesse dos Enfermeiros em uma formação tão prolongada.

Entretanto, a ausência de Cursos de Licenciatura e a crescente demanda por enfermeiros docentes propiciou o aumento da Pós-Graduação ou Especialização lato sensu em Formação Docente (SANTOS et al, 2011). Essa formação pedagógica está prevista nas Diretrizes Curriculares 
Nacionais dos Cursos de Graduação em Enfermagem / Resolução CNE/CES $n^{\circ} 3 / 2001$, em seu Artigo $6^{\circ}$ inciso III, alínea "d", que dispõe sobre conteúdos pertinentes à capacitação Pedagógica do enfermeiro, que lhe dará suporte para planejar, implementar e participar de forma ativa na formação de outros profissionais, e em programas de educação e promoção à saúde. Essas qualificações profissionais possuem menor duração, entre 18 e 24 meses, e são ofertadas por algumas Universidades Federais, gratuitamente, por terem como propósito a inclusão.

Já o PROFAE teve em sua estruturação o Curso de Especialização em Formação Pedagógica em Educação Profissional na Área de Saúde Enfermagem (CEFPEPE), que corresponde ao componente dois (2) do projeto. Este foi instituído em caráter emergencial e atualmente vem se desenvolvendo na modalidade de "Ensino à Distância" em algumas Universidades brasileiras. O componente um (1) tratava do ensino técnico e exigia para tal o desempenho de professores, no caso Enfermeiros com essa qualificação agregada à oferta. No momento, o componente um (1) foi extinto e o componente dois (2) ainda está em desenvolvimento.

Em seus cinco primeiros anos, o PROFAE ultrapassou a meta de formar 12.000 Enfermeiros docentes, habilitando 13.601 profissionais Especialistas em Pedagogia para atuarem na educação profissional. A base da proposta foi uma resolução do Conselho Nacional de Educação (CNE) feita em 1997, em vigor até o momento, que autoriza, em caráter especial, a realização de programas para suprir a falta de professores habilitados nas escolas.

Inicialmente, o PROFAE/CEFPEPE focava restritamente a formação de Enfermeiros docentes, porém no ano de 2012 houve a ampliação do público alvo com a abertura da oportunidade da formação pedagógica para profissionais graduados em Enfermagem, Educação Física, Farmácia, Fisioterapia, Fonoaudiologia, Medicina, Nutrição, Odontologia, Psicologia, Serviço Social, Terapia Ocupacional e outros profissionais da área da saúde, previstos na resolução 287/98 do Conselho Nacional da Saúde, preferencialmente vinculados à rede de educação profissional em saúde ou à rede de serviços de saúde.

Ao integrar novos profissionais, houve uma remodelagem na estruturação desta especialização que passou a ser denominada: Formação Pedagógica em Educação Profissional na Área da Saúde (CEFPEPS). Este formato surgiu a partir da necessidade da construção de conhecimentos pautados no aprofundamento teórico que produzisse práticas e ações interdisciplinares para responder a complexa variedade de demandas observadas atualmente na saúde (CARPES et al, 2016).

A interdisciplinaridade consiste na troca de conceitos, teorias e métodos entre as diferentes saberes (TEIXEIRa, 2007). O CEFPEPS representa um avanço nessa nova forma de pensar e fazer educação em 
saúde ao entender a necessidade de balizar a formação pedagógica não apenas de enfermeiros, dando vistas à superação da linearidade e fragmentação do saber disciplinar.

A Resolução COFEN n. 389/2011 altera a nomenclatura do Curso de Especialização em Formação Pedagógica em Educação Profissional em Enfermagem para Especialização em Educação em Enfermagem / Saúde para "Docência para a Educação Profissional".

O que é possível observar é que, apesar dos esforços nas políticas para a formação de professores, as soluções emergenciais são predominantes. Atualmente não existe professor suficiente para dar sustentabilidade pedagógica ao crescimento da educação profissional previsto pelo Programa Nacional de Acesso ao Ensino Técnico e Emprego (PRONATEC) e pelo Plano Nacional de Educação (PNE) 2011-2020 (CNE, 2009).

Com isso, algumas Secretarias Estaduais de Educação (SEE), apesar de exigirem a licenciatura para que enfermeiros atuem como docentes na profissionalização em enfermagem emitem autorizações a título precário permitindo provisoriamente 0 exercício docente de não licenciados, renovando-as anualmente, quantas vezes forem necessárias. Em contraponto, o mesmo órgão, diferentemente do COFEN e de outras SEE, não reconhece a Especialização Pedagógica como formação para a docência, o que necessita ser revisto, pois observa-se certa ambiguidade nessa conduta.

A Carta de Belém para a Educação em Enfermagem Brasileira, reforça a formação Pedagógica do enfermeiro ao levantar a necessidade de retomada e ampliação do debate sobre a Licenciatura para a Educação Técnica Profissional na área, prevendo a implementação de uma política (também) emergencial e indutora de formação de licenciados em Enfermagem e de qualificação permanente do enfermeiro-docente, para o exercício da docência na Educação Técnica Profissional, bem como uma fiscalização que assegure a participação do enfermeiro qualificado pedagogicamente na Formação Técnica Profissional de Nível Médio (CARTA DE BELÉM, 2012).

Os enfermeiros que se incubem da necessária e desafiadora tarefa de ensinar uma profissão de tamanha relevância social, têm o dever e a obrigação de desempenhar a função com capacidade para tal, exercendo papel fundamental na mediação do conhecimento e de sua aplicabilidade.

A apropriação de saberes científicos e pedagógicos possibilita contextualizar teoria e prática, visando desenvolver no educando autonomia, senso crítico e reflexivo para que possa atuar no mundo do trabalho em constante mudança e vencer o grande desafio, o cuidar (GUBERT; DOPRADO, 2011). No entanto, há evidências de que os enfermeiros podem estar se inserindo na docência sem qualificação devido a questões que vão 
para além das dificuldades de acesso aos cursos que os qualificam para a função.

\subsection{Revelações das publicações científicas pesquisadas}

Em trabalho com objetivo semelhante a este, foi possível verificar que são poucos os estudos que tratam essencialmente do enfermeiro em atividade docente no ensino profissionalizante (MAISSIAT; CARRENO, 2011). Isso também foi observado nessa revisão e pode ser um alerta de que o tema, apesar de sua relevância, desperta pouco interesse por parte dos pesquisadores, apesar da realidade demonstrar a necessidade de abordagens qualitativas e quantitativas que problematizem a questão.

A despreocupação do enfermeiro docente frente a sua formação e competência para o ensino profissionalizante também foi observada diante da escassez de professores que reciclam seus conhecimentos, que se especializam na educação e que buscam nas pesquisas científicas uma forma de melhorar e atualizar sua prática profissional (GUBERT; DOPRADO, 2011). Sendo assim, o investimento no desenvolvimento da qualificação para a docência em enfermagem tende a ser um grande desafio, considerando que o desejo intrínseco e extrínseco de projeção na área de ensino e aprendizagem parece ainda não estar desperto nesse grupo investigado.

A necessidade de qualificação para atuar na docência em enfermagem foi acentuada a partir da abertura de novos cursos no sistema público e privado de ensino profissionalizante, o que implicou em demanda de um corpo docente preparado (DE-SOUZA; PREZOTO, 2013). A ampliação da oferta de vagas gratuitas ou financiadas em programas de governo que favorecem a formação técnica também contribuiu para o aumento da demanda de trabalho para o enfermeiro, expandindo o mercado para 0 exercício docente.

Contudo, apesar da crescente expansão, o trabalho como professor do nível TE é relegado à função secundária. Assim, ensinar não é a atividade principal do enfermeiro, especialmente em virtude do modelo assistencial e educacional que se instalou no país, o qual valoriza as ações diretas à saúde em detrimento a formação e a atuação pedagógica, desmotivando a participação desse profissional em projetos que o preparem para o exercício docente (LIMA; APPOLINÁRIO, 2011).

Estudantes, concomitantemente, de Bacharelado em Enfermagem e Licenciatura, participaram de uma pesquisa com vistas à expectativa do exercício profissional após a formação acadêmica. O resultado evidenciou que estes visam primordialmente à possibilidade de atuação na assistência, munidos da formação adicional de educador (SANTOS et al, 2011). Portanto, a formação pedagógica não tem foco e aplicabilidade direta na atuação docente em Cursos Técnicos em Enfermagem. É preocupante formar 
enfermeiros licenciados que não objetivam exercer a docência, apenas a educação permanente em serviço (que é tão importante quanto), porém esse fato ocorre enquanto não licenciados exercendo a função de ensino sem preparo adequado é uma realidade vigente.

Os enfermeiros egressos da graduação e ingressos como professores dos Cursos Técnicos em Enfermagem não estão adequadamente preparados, visto que há falta de conhecimento do processo de ensinar e falta de suporte didático pedagógico (SANTOS et al, 2014). Na graduação em enfermagem poucos cursos proporcionam uma base sólida para as atividades de educação, informação e orientação. O currículo é essencialmente de caráter assistencialista, sendo que as disciplinas voltadas para o ensino são ministradas com menor crédito ou são inexistentes, tornando a formação didático/pedagógica insuficiente para atuação em sala de aula (FERREIRAJúNIOR, 2008).

Os dados de um estudo informam que a grande maioria dos professores de um Curso Técnico em Enfermagem, iniciou as atividades docentes sem qualquer preparo prévio para a função e suas colocações indicam que essa ausência de formação acarreta-lhes dificuldades de diferentes naturezas, relacionadas à organização e condução do ensino (SANTOS et al, 2014). Reforçando esse achado, uma investigação recente, realizada com docentes, chama a atenção para a percepção da grande desarticulação do conhecimento didático pedagógico com a prática realizada em sala de aula, evidenciando o déficit nesta área que é considerada como saber fundamental para a qualidade do processo de ensino e aprendizagem no curso profissionalizante em enfermagem (SANTOS et al, 2014).

Destaca-se que a seleção de professores para o ensino profissionalizante, em alguns casos, é feita pela eloquência do profissional (FERREIRA-JÚNIOR et al; 2015, COLONI et al; 2016). Não é usual as escolas, exigirem preparo docente e experiência profissional, essencial para que se possa constituir e proporcionar a construção de uma visão plural da enfermagem e de seus entes.

Infere-se que as escolas de nível TE também podem ter responsabilidade direta na questão da ausência de formação pedagógica do Enfermeiro. Esta prática é reforçada pela autorização de algumas SEE, com a liberação de autorizações provisórias e pela própria escassez de profissionais com esse perfil.

Complementando a problemática, as escolas não proporcionam aos seus docentes uma formação inicial ou continuada, desconsiderando a importância dos saberes didático-pedagógico, bem como a evolução dos conhecimentos técnicos científicos e das práticas de saúde, o que demanda a constante necessidade de atualização de seus professores e a imperativa participação da escola que os agrega em algum tipo de incentivo que proporcione a melhor qualificação. 
É relevante também considerar que uma das lacunas existentes no preparo pedagógico para a docência consiste na interdisciplinaridade, uma vez que este é um dos princípios da educação profissional e sua ausência pode interferir negativamente no desempenho didático do docente (SOUZA et al, 2016). Nas reformas de ensino do MEC, esse princípio está colocado nos diversos documentos divulgados após a LDB/96, no entanto, as escolas estão com dificuldade de promover essa discussão sobre as práticas interdisciplinares que reforçam a formação pedagógica de seus docentes (PONTUSCHKA, 2015). Para alunos da Licenciatura em Enfermagem, o curso foi percebido como uma oportunidade de vivenciar a interdisciplinaridade, conhecendo novos olhares, adquirindo uma visão plural do mundo, no que concerne somente a área da saúde (CORDEIRO et al, 2015).

Portanto, há necessidade de ampliar a discussão acerca do tema, sobretudo, no que se refere ao papel da gestão e a qualificação pedagógica necessária para a efetividade da docência em saúde, que, mesmo com todas as diretrizes norteadoras e reestruturadoras desse ensino, não garantem, de fato, a formação do profissional com o perfil pretendido (FREITAS et al, 2016). Para além, ainda se faz relevante considerar que os saberes da formação docente inicial são essenciais, mas também podem ser insuficientes, razão pela qual o processo de educação continuada torna-se cada vez mais veemente para responder às demandas contemporâneas com competência e profissionalismo.

Mesmo enfermeiros licenciados ou especialistas em pedagogia, precisam estar atentos às mudanças ocorridas na educação e na saúde que forçam adaptações à realidade presente na sociedade em que se inserem (FONTOURA; SUSSEKIND, 2014). Assim, a continuidade ao processo de formação para o trabalho torna-se imperativa na trajetória de todo enfermeiro docente. Este necessita estar inserido em um processo permanente de educação para construção do saber ser e do saber fazer docente. Nesse percurso, não podem cessar as possibilidades de desenvolvimento e continuidade dos saberes que qualificam o profissional para o exercício de uma função dinâmica por tratar-se de uma área onde o conhecimento se amplia e se renova constantemente.

\section{CONCLUSÃO}

As instituições superiores que formam os graduados em enfermagem e as escolas profissionalizantes que os contrata como docentes precisam reconhecer a sua responsabilidade direta em proporcionar a formação adequada dos enfermeiros que pretendem exercer a docência ou para aqueles que já se engajaram nesta tarefa de relevância social. 
A oferta da qualificação para a docência é premissa para que 0 ato de educar se efetive. O preparo didático/pedagógico prévio de enfermeiros é essencial para proporcionar adequado conhecimento àqueles que interveem de forma íntima, integral e integrada nos processos de saúde e doença, como os Técnicos em Enfermagem.

O despreparo docente é a raiz de um problema que em última instância afeta a qualidade dos cuidados prestados à saúde da população brasileira. É preciso avançar nos (pré)conceitos do ensino em cursos profissionalizantes em enfermagem, inicialmente desmistificando a questão da desvalorização do professor, pois muito se tem feito para elevar a categoria, inclusive com a oferta de melhores oportunidades na área.

No entanto, ao que parece os próprios enfermeiros relegam a docência à função secundária. Assim, não investem na Licenciatura ou na Especialização Pedagógica, apesar de muitos exercerem a área do ensino, desconsiderando que sua fragilidade pedagógica é determinante para o preparo, também frágil, dos Técnicos em Enfermagem que irão estar sob sua gestão nas instituições de saúde.

Outra questão relevante é a relação das escolas profissionalizantes com seus professores. Para que mudanças possam ser refletidas na práxis da enfermagem é preciso estabelecer outras e novas relações, revendo a real beneficência social ao contratar enfermeiros docentes sem qualificação pedagógica prévia.

Estas instituições também precisam se ater a necessidade do suporte interdisciplinar para a formação de sua equipe docente com vistas à integralidade do processo de ensino e aprendizagem. Por vezes, apenas enfermeiros se incubem da tarefa de lecionar para a própria categoria, desconsiderando os diversos saberes que integram a formação dos técnicos em enfermagem, visto que esses profissionais atuam de maneira generalista na ampla e vasta área da saúde.

Há de se entender que a partir do momento que a exigência da formação adequada para docência for instituída, provavelmente os enfermeiros interessados se sentirão motivados a investir na adequada formação para tal exercício. Bem como as instituições que os contrata, terá maior credibilidade quanto à qualidade da educação oferecida aos discentes.

Espera-se com esse trabalho provocar a reflexão sobre a problemática do corpo docente no que tange ao seu (des)preparo pedagógico para 0 exercício da profissão de professor. O intuito é contribuir positivamente para a sociedade no processo de educação formal em saúde, sendo este apenas um, dos pontos necessários para alavancar a qualidade de vida da população brasileira. 


\section{REFERÊNCIAS}

BRASIL. Conselho Nacional de Educação. Indicações para subsidiar a construção do Plano Nacional de Educação: 2011-2020. Brasília (DF), 2009.

Decreto n. 5.154, de 23 de julho de 2004. Regulamenta $\circ \S 2^{\circ}$ do artigo 36 e os arts. 39 a 41 da Lei n. 9.394, de 20 de dezembro de 1996, que estabelece as diretrizes e bases da educação nacional, e dá outras providências. Diário Oficial República Federativa do Brasil, Brasília (DF), jul. 2004.

Lei $\mathrm{n}^{\circ}$ 2.604, de 17 de setembro de 1955. Regula o Exercício da Enfermagem Profissional. Diário Oficial República Federativa do Brasil, Brasília (DF), set. 1955.

Lei n.7.498, de 25 de junho de 1986. Dispõe sobre a regulamentação do exercício da Enfermagem e dá outras providências. Diário Oficial da União, Brasília (DF), v. 1, n. 9273, jun. 198

Ministério da Educação. Câmara de Ensino Superior. Parecer n. 837/68 Criação do Curso de Licenciatura em Enfermagem. Brasília (DF), MS, 1968.

Lei 9.394 de 20 de dezembro de 1996. Diário Oficial da República Federativa do Brasil. Brasília (DF), 1996.

- Ministério da Saúde. Qualificação profissional e saúde com qualidade. Formação (Projeto de profissionalização dos trabalhadores da área de Enfermagem). Brasília (DF), Ministério da Saúde, 2001.

Resolução CNE/CES 3/2001. Diário Oficial da União - DOU, Brasília (DF), Câmara de Educação Superior, Seção 1, p. 37, nov. 2001.

Resolução CNE/CEB N. ㅇ 02, de 26 de junho de 1997. Dispõe sobre os programas especiais de formação pedagógica de docentes para as disciplinas do currículo do ensino fundamental, do ensino médio e da educação profissional em nível médio. MS/Secretaria de Educação Média e Tecnológica, Unidade de Coordenação de Programas, Programa da Expansão da Educação Profissional. Brasília (DF), 2001.

Ofício circular de 02/2010-CGOC/DESUP/SESU/MEC, 2010.

BUENO, S. M. V. et al. Enfermeiro professor e o ensino médio em enfermagem. In: Encontro de Formação de Professores de Ensino Médio em Enfermagem Política de Formação de Recursos Humanos de Nível Médio em Enfermagem, 2., 1997, Ribeirão Preto. Anais... Ribeirão Preto: Gráfica São Gabriel, 1997. p. 103.

CARPES, A. D. et al. A construção do conhecimento interdisciplinar em saúde. Disciplinarum Scientia| Saúde, v. 13, n. 2, p. 145-151, 2016. 
CARTA DE BELÉM: para a educação em enfermagem brasileira. Rev. bras. Enferm. Brasília (DF), v. 65, n. 4, p. 696-698, 2012.

CHIECO, N. W. O descompasso entre as mudanças tecnológicas e os currículos adotados nas escolas técnicas. Tecnologia Educacional, Rio de Janeiro, p. 9-17, 1987/88/89.

COFEN. Conselho Federal de Enfermagem. Decreto Lei 94.406 de 8 de junho de 1987. Documentos Básicos de Enfermagem. São Paulo, COREN, 2000.

Resolução n.389, de 18 de outubro de 2011. atualiza, no âmbito do Sistema COFEN/COREN, os procedimentos para registro de título de pósgraduação lato e stricto sensu concedido a Enfermeiros e lista as Especialidades. Brasília (DF), 2011.

Total de inscritos. Brasília; mar. 2017.

COLONI, C. S. M. et al. Prática Pedagógica na Educação Profissional de Nível Médio em Enfermagem. Cogitare Enfermagem, v. 21, n. 1, p. 1-9, 2016.

CORDEIRO, $M$. et al. $O$ significado do curso de licenciatura para enfermeiros egressos da Universidade Federal de Pernambuco. CIAIQ, v. 1, 2015.

DE-SOUZA, E. G., PRESOTO, L. H. O perfil dos docentes do ensino técnico profissionalizante em enfermagem. Rev. Científica de Enfermagem, v. 3, n. 9, p. 23-30, 2013.

DUARTE, M. J. R. S. Formação pedagógica do enfermeiro para o ensino de nível médio. Rev. Enferm. UERJ, v. 9, n. 1, p. 52-5, 2009.

FREITAS, D. et al. Saberes docentes sobre processo ensino-aprendizagem e sua importância para a formação profissional em saúde. Interface Comunicação, Saúde, Educação, v. 20, n. 57, p. 437-448, 2016.

FERREIRA-JÚNIOR, M. A. et al. O início das atividades de ensino do professor enfermeiro. InterSciencePlace, v. 1, n. 12, 2015.

FERREIRA-JÚNIOR, M. A. Os reflexos da formação inicial na atuação dos professores enfermeiros. Revista Brasileira de Enfermagem, v. 61, n. 6, 2008.

FONTOURA, H. A., SUSSEKIND, M. L. Dossiê formação docente: Memórias, narrativas e cotidianos. Revista Teias, v.15, n.37, p. 4-12, 2014.

FRIEDLANDER, M. R. et al. O ensino de enfermagem em nível médio./Apresentado ao 11. In: Congresso da Associação Médica Brasileira, São Paulo, 1992.

GÓES, F. S. N. et al. Necessidades de aprendizagem de alunos da Educação Profissional de Nível Técnico em Enfermagem. Rev. bras. Enferm, v. 68, n. 1, p. 20-25, 2015. 
GUBERT, E., Do Prado, M. L. Desafios na prática pedagógica na educação profissional em enfermagem. Rev. Eletrônica de Enfermagem, v. 13, n. 2, p. 285-95, 2011.

IBGE. Instituto Brasileiro de Geografia e Estatística. Censo Demográfico. Rio de Janeiro: Diretoria de Pesquisas, 2010.

LIMA, E. C., APPOLINÁRIO, R. S. A educação profissionalizante em enfermagem no Brasil: desafios e perspectivas. Rev enferm UERJ, v. 19, $n$. 2, p. 311-6, 2011.

MAISSIAT G. S., CARRENO, I. Enfermeiros docentes do ensino técnico em enfermagem: Uma revisão integrativa. Rev. Destaques Acadêmicos, v. 2, n. 3, 2011.

PONTUSCHKA, N. N. Interdisciplinaridade: aproximações e fazeres. Terra livre, v. 1, n. 14, p. 100-124, 2015.

ROTHER, E. D. Revisão sistemática $X$ revisão narrativa. Acta paulista de enfermagem, v. 20. N. 2, p. 5-6, 2007.

SANTOS, L. M. C. R. et al. A Licenciatura em Enfermagem no Brasil (19682001): Uma Revisão de Literatura. Hist. enferm., Rev. Eletrônica, v. 5, n. 2, p. 224-238, 2014.

SANTOS, S. M. R. et al. Licenciatura e Bacharelado em Enfermagem: experiências e expectativas de estudantes. Rev. gaúch. Enferm, v. 32, n. 4, p. 711-718, 2011.

SECAF, V. A licenciatura em enfermagem e a prática de ensino: uma revisão crítica de sua evolução na Universidade de São Paulo. Tese de Doutorado. Universidade de São Paulo: Escola de Enfermagem, 1987.

SOUZA, D. M. et al. Formação docente na educação profissional técnica de nível médio: uma revisão integrativa da literatura. Interfaces da Educação, v. 7, n. 20, p. 211-235, 2016.

TEIXEIRA, E. F. B. Emergência da inter e da transdisciplinaridade na universidade. In: Audi J. L. N.; Morosini M. C. (Org.). Inovação e interdisciplinaridade na universidade. Porto Alegre, RS: EDIPUCRS, p. 5890, 2007.

VALENTE, G. S. C. A formação do enfermeiro para o ensino de nível médio em Enfermagem: Uma questão de competências. Tese de Doutorado. UFRJ. Escola de Enfermagem Anna Nery, 2006. 